\title{
Low Incidence of Rhythm Disturbance Following Percutaneous Closure of Ventricular Septal Defects Using the Amplatzer Device at Immediate-to-Long-Term Follow Up
}

\author{
Muhammad Dilawar, $\mathrm{MD}^{1 *}$, Muhammed Riyas K Rahmath, $\mathrm{MD}^{2}$, Assad Al-Hroob, MD, \\ Howaida G. El-Said, MD ${ }^{4}$, Amal El Sisi, MD ${ }^{5}$, Salwa Morcos, MD , Mohammed Numan, MD ${ }^{7}$ \\ ${ }^{1}$ Division of Pediatric Cardiology, Hamad General Hospital, Doha, Qatar \\ 2 Division of Pediatric Cardiac Surgery, Hamad General Hospital, Doha, Qatar \\ ${ }^{3}$ University of Texas, Health Science Center, San Antonio, Texas, USA \\ ${ }^{4}$ Division of Cardiology, Rady Children's Hospital, University of California, San Diego, USA \\ ${ }^{5}$ Cairo University Pediatric Hospital, Cairo, Egypt \\ ${ }^{6}$ Division of Pediatric Cardiology, Rush University Hospital, Chicago, USA \\ ${ }^{7}$ Division of Pediatric Cardiology, University of Texas, Houston, Texas, USA
}

\begin{abstract}
Background: There have been concerns of heart block and rhythm disturbances following transcatheter closure of VSD. Our aim in this study is to evaluate rhythm and conduction disturbances following percutaneous device closure of ventricular septal defects at immediate and long-term follow up.

Methods: A retrospective review of all patients who underwent transcatheter VSD closure using an Amplatzer device from January 2003 to September 2012 at Hamad General Hospital in Qatar was performed, including catheterization data, echocardiograms, and EKGs at latest follow up.

Results: Of 49 patients, 45 ( 35 perimembranous and 10 muscular) were successfully closed. Median age was 8.5 years and median weight was $24 \mathrm{~kg}$. The median VSD size was $6 \mathrm{~mm}$. Median pulmonary to systemic blood flow was 1.4:1, and the median Amplatzer device size was $8 \mathrm{~mm}$. There was no immediate or late mortality, and the closure rate was $91.8 \%$, whereas the procedure was unsuccessful or abandoned in $8.2 \%$ of cases. At a mean follow up of $\mathbf{5 4 . 5}$ months, echocardiography
\end{abstract}

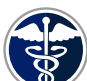

Fax +1 2037853346

E-Mail: jshd@scienceinternational.org

http://structuralheartdisease.org/ (c) 2016 Journal of Structural Heart Disease Published by Science International Corp. ISSN 2326-4004

Accessible online at:

http://structuralheartdisease.org/ revealed complete ventricular septal defect closure in $41(91 \%)$ patients, and $4(9 \%)$ patients had a small residual shunt. An electrocardiography median follow up of $\mathbf{6 1 . 9}$ months revealed normal sinus rhythm in 37 (84\%) cases, incomplete right bundle branch block in $1(2 \%)$ case, complete right bundle branch block in $4(8 \%)$ cases, and left bundle branch block in $2(4 \%)$ study group cases. However, complete atrioventricular block was observed in one $(2.9 \%)$ of the perimembranous VSD patients.

Conclusions: Transcatheter closure of perimembranous and muscular ventricular septal defects is a safe and effective procedure. Rhythm disturbance at late follow up is comparable with surgical closure rhythm disturbances and is less frequent than previously found in some transcatheter closure reports.

Copyright @ 2016 Science International Corp.

\section{Key Words}

Congenital heart defects - Perimembranous VSD • Muscular VSD - Complete atrioventricular block • VSD device closure • Amplatzer VSD device

*Corresponding Author:

Muhammad Dilawar, MD

Pediatric Cardiology

Hamad General Hospital \& Weill Cornell Medical College at Qatar

PO Box 3050, Doha, Qatar

Tel.: +00974 55916554, Fax: +00974 44391622, E-Mail: dilawarmd@yahoo.com 


\section{Introduction}

Ventricular septal defect (VSD) is the most common congenital heart disease (CHD), constituting $30-40 \%$ of all congenital heart diseases [1]. Symptomatic patients need medical management and probably surgical closure if medical therapy fails. Although advances in surgical, anesthetic, and postoperative care have made surgical closure of VSD safer, morbidities like cerebrovascular accidents, seizures, chorea/athetosis, lung collapse, phrenic nerve injury, and junctional ectopic tachycardia are still concerns following open heart surgery $[2,3]$. One of the serious complications of surgery is complete atrioventricular block (CAVB), which has been reported from $0.7 \%$ to $3.1 \%$ for membranous and outlet VSDs [4, 5]. Transcatheter approach to close such VSDs has been an attractive option to avoid these morbidities. Ten years after the initial transcatheter closure, in 1998, the Amplatzer muscular occluder had revolutionized the percutaneous VSD closure with favorable outcomes $[6,7]$. Approximately two-thirds of VSDs are in the perimembranous (pmVSD) location, and there have been growing concerns about complete heart block at late follow up of percutaneous membranous VSD closure. A special Amplatzer membranous VSD device with an eccentric left ventricular disc was designed for the closure of pmVSDs with good initial results [8-10]. Occasionally, pmVSD with aneurysmal tissue can be closed with an Amplatzer duct occluder (ADO) $[11,12]$. The aim of this study is to evaluate rhythm disturbances caused by transcatheter VSD devices at immediate and long-term follow up.

\section{Materials and Methods}

This is a retrospective observational study to assess immediate to long-term rhythm follow up of percutaneous closure of muscular VSD (mVSD) and pmVSD with different types of Amplatzer occluders. All patients who were taken to the catheterization laboratory for attempted VSD closure using an Amplatzer device during the period of January 2003 and September 2012 at Hamad General Hospital, Doha, Qatar, were included. Inclusion criteria for percutaneous VSD closure was a muscular or pmVSD with clinical and or echocardiographic evidence of significant left to right shunt or a significant residual VSD after surgical repair. Exclusion criteria for percutaneous VSD closure was a body weight less than $7 \mathrm{~kg}$, right to left shunt across the VSD, a pmVSD with less than 2-mm subaortic rim on long axis echocardiographic view, VSDs asso- ciated with complex heart lesions, and or contraindication to antiplatelet therapy.

Hospital IRB approval for the study was obtained. Data collected included patient's demographics, echocardiographic and cardiac catheterizations data (Tables 1 and 2). Electrocardiographic (EKG) data was collected and analyzed to evaluate the rhythm disorders in this cohort (Tables 3 and 4).

Previously described technique for VSD closure was used [14]. Echocardiogram and EKG on the first post-catheterization day and at 1, 3, 6, and 12 months, and then yearly were reviewed for any conduction abnormality, residual VSD shunt, aortic regurgitation (AR), or tricuspid regurgitation (TR).

The data were initially entered into an Excel spread sheet and subsequently imported into the JMP Statistics Package v8.0.1 (SAS Corp., USA). All statistical analyses were carried out within JMP. In addition to basic descriptive statistics (mean, medians, ranges, standard deviations, and counts of missing data), both Pearson's and Spearman's correlation coefficients (and their associated $\mathrm{p}$ values) were calculated to explore the linear correlations between specific pairs of variables, and the correlations quoted here are Spearman's rho. Potential outliers were identified by eye (based on JMP scatter plots) and aided by the superimposition of a $95 \%$ bivariate normal density ellipse generated by JMP. The statistical significance of the differences between the means of continuous variables was explored using the $t$ test (for equal or unequal variances as applicable) and Wilcoxon's test, and the p values quoted here are for Wilcoxon's. The alpha-level for statistical significance was set to be 0.05 for all tests.

\section{Results}

VSD device closure was attempted on 49 patients with successful closure achieved in 45 patients (success

Table 1: Patient demographics, VSD size, device size, Qp:Qs, RVSP, fluoro time, and procedure time

\begin{tabular}{llll}
\hline & Mean & Median & Range \\
\hline Age (years) & 11.2 & 8.5 & $2-36.7$ \\
Weight $(\mathrm{kg})$ & 35.5 & 24 & $10-106$ \\
VSD size $(\mathrm{mm})$ by TTE & 7.2 & 7 & $3-14$ \\
VSD size $(\mathrm{mm})$ by TEE & 7.5 & 6 & $4-15$ \\
VSD size (mm) by LV angiography & 6.2 & 6 & $3-14$ \\
Device size (mm) & 8.7 & 8 & $4-18$ \\
Qp:Qs & 1.5 & 1.4 & $1-3$ \\
RVSP (mm Hg) & 31.5 & 28.5 & $20-50$ \\
Fluoro time (min) & 47.11 & 41.5 & $17-138$ \\
Procedure time (min) & 145 & 132.5 & $46-310$ \\
\hline
\end{tabular}

$\mathrm{TTE}=$ transthoracic echo; TEE = transesophageal echo; Qp:Qs = pulmonary to systemic blood flow ratio; RVSP = right ventricular systolic pressure. 
Table 2: Comparison of muscular and membranous VSD groups and their mean values

\begin{tabular}{lllllllll}
\hline Type of VSD & Age (years) & $\mathbf{W t}(\mathbf{k g})$ & $\begin{array}{l}\text { VSD TEE } \\
(\mathbf{m m})\end{array}$ & $\mathbf{Q p : Q s}$ & $\begin{array}{l}\text { Device Size } \\
(\mathbf{m m})\end{array}$ & $\begin{array}{l}\text { Proc. Time } \\
(\mathbf{m i n})\end{array}$ & $\begin{array}{l}\text { Fluoro Time Follow Up } \\
(\mathbf{m i n})\end{array}$ \\
\hline $\begin{array}{l}\text { Muscular } \\
\text { Membranous }\end{array}$ & 13.2 & 46.5 & 6.67 & 1.65 & 8.25 & 159.16 & 61 & 54.78 \\
$\begin{array}{l}\text { P value } \\
\text { M }\end{array}$ & 0.31 & 36.35 & 6.66 & 1.4 & 8.14 & 137.81 & 43.93 & 64.03 \\
\hline
\end{tabular}

Wt = weight; TEE = transesophageal echo; Qp:Qs = pulmonary to systemic blood flow ratio; Proc time = procedure time

rate of $91.8 \%$ ); the female to male ratio was 1.14 . Among these 45 VSD closure cases, 35 were perimembranous (78\%) (34 native and 1 surgical residual) and 10 muscular (9 native and 1 surgical residual) defects. The pmVSDs were closed using 23 pmVSD devices, 6 muscular VSD devices, and 6 Amplatzer duct occluders (ADO), whereas the muscular VSDs were closed with nine muscular VSD devices and one ADO device. The ADO devices were used only in tunnel shape aneurysmal VSDs. Ten (22\%) patients had associated cardiac anomalies including patent ductus arteriosus in one, pulmonary valve stenosis in four, mild mitral stenosis in one, additional small muscular VSDs in two, and bicuspid aortic valve in two.

In two out of four unsuccessful cases, the VSD delivery sheath could not be advanced through VSD due to aneurysmal tissue; in one case, there was device

Table 3: New onset rhythm disorders in the membranous VSD group

\begin{tabular}{|c|c|c|c|c|}
\hline $\begin{array}{l}\text { Rhythm Disorder } \\
\text { \& Patient Number }\end{array}$ & $\begin{array}{l}\text { Age } \\
\text { (years) }\end{array}$ & $\begin{array}{l}\text { Weight } \\
\text { (kg) }\end{array}$ & $\begin{array}{l}\text { VSD Size } \\
(\mathrm{mm}) \text { by } \\
\text { TEE }\end{array}$ & $\begin{array}{l}\text { Device } \\
\text { Size } \\
(\mathrm{mm})\end{array}$ \\
\hline \multicolumn{5}{|l|}{ CRBBB - 4} \\
\hline 1 & 17.5 & 57 & 12 & 12 \\
\hline 2 & 9.4 & 18 & 14 & 16 \\
\hline 3 & 5 & 18 & 8 & 10 \\
\hline 4 & 5.7 & 14 & 4 & 4 \\
\hline CLBBB - 1 & 5 & 16 & 6 & 6 \\
\hline CAVB - 1 & 5 & 17 & 12 & 12 \\
\hline EAT - 1 & 27.2 & 54 & 4 & 4 \\
\hline V. Tach - 1 & 14.3 & 77 & 11 & 10 \\
\hline
\end{tabular}

Dilawar, M. et al. related aortic regurgitation and the device was retrieved with no residual regurgitation, and in another case, there was transient complete heart block that reverted to normal sinus rhythm after device removal. All four patients who failed device closure were referred for surgical closure.

At the time of VSD closure, the median age of the study group was 8.5 years (range 2-36.7 years) and the median weight of $24 \mathrm{~kg}$ (range 10-106 kg). The median VSD size by transthoracic echocardiogram (TTE), TEE, and by LV angiogram was 7, 6, and $6 \mathrm{~mm}$, respectively, and the device size was with a median of $8 \mathrm{~mm}$ (range 4-18). The median ratio of systemic to pulmonary blood flow (Qp:Qs) was 1.4 (range 1-3) and the median right ventricular systolic pressure was $28.5 \mathrm{~mm} \mathrm{Hg}$ (range $20-50 \mathrm{~mm} \mathrm{Hg}$ ). The median fluoro and the median procedure times were 41.5 minutes and 132.5 minutes, respectively (Table 1 ).

There was no significant correlation between weight and VSD size with fluoroscopy time [when outliers were removed the correlation coefficient was $0.282(p=0.11)$ and $0.066(p=0.73)$, respectively].

Table 4: New onset rhythm disorders in the muscular VSD group

\begin{tabular}{lllll}
\hline $\begin{array}{l}\text { Rhythm Disorder } \\
\text { \& Patient Number }\end{array}$ & $\begin{array}{l}\text { Age } \\
\text { (years) }\end{array}$ & $\begin{array}{l}\text { Weight } \\
(\mathbf{k g})\end{array}$ & $\begin{array}{l}\text { VSD Size } \\
(\mathbf{m m}) \text { by } \\
\text { TEE }\end{array}$ & $\begin{array}{l}\text { Size } \\
(\mathbf{m m})\end{array}$ \\
\hline ICRBBB -1 & 10.5 & 37 & 6 & 6 \\
CLBBB - 1 & 3.5 & 23 & 6 & 6 \\
PVCS - 1 & 8 & 21 & 4 & 4 \\
\hline
\end{tabular}

TEE = transesophageal echo; CLBBB = complete left bundle branch block; ICRBBB = incomplete right bundle branch block; PVCs = premature ventricular contractions. 


\section{Base line EKG}

At baseline, all patients had 12-lead EKG prior to VSD closure. EKG was normal in 40 (89\%) patients and abnormal in $5(11 \%)$ patients [4 incomplete right bundle branch block (ICRBBB) and 1 complete right bundle branch block (CRBBB) (Figure 1)].

\section{Latest EKG}

During 8 year follow up, EKG findings were analyzed in all 45 subjects. At a median follow up of 61.9 months, EKG revealed one patient with muscular VSD had developed ICRBBB. There were total 5 patients with CRBBB at the latest follow up. Out of these 5 patients, 3 patients had new onset CRBBB, fourth patient had progression of base line ICRBBB to CRBBB and in the fifth patient the base line CRBBB persisted as it is at the latest follow up. All the patients with CRBBB were having pmVSD and they received a pmVSD Amplatzer device of mean size $10.5 \mathrm{~mm}$ at a mean age of 9.4 years and weight of $26.7 \mathrm{~kg}$. There was no CRBBB observed in muscular VSD patients at follow up.

Complete left bundle branch block (CLBBB) was seen in two (4\%) patients in this cohort, one had pmVSD and one had muscular VSD. Both patients received muscular VSD Amplatzer devices ( $6 \mathrm{~mm}$ size) and their mean age and weight were 4.3 years and $19.5 \mathrm{~kg}$, respectively.

Complete atrioventricular block occurred in one (2.9\%) of the patients in the perimembranous VSD group. This patient received a $12-\mathrm{mm}$ membranous type Amplatzer device, and his age and weight were 5 years and $17 \mathrm{~kg}$, respectively. He developed CRBBB immediately after the procedure, which persisted for 6 months; at 1 year follow up, he was found to have CAVB and underwent placement of a permanent pacemaker.

Other arrhythmias observed in the pmVSD group included 3 beats run of ventricular tachycardia in one patient and ectopic atrial tachycardia in another patient. Occasional premature ventricular contractions were observed in one of the cases from the muscular VSD group (Tables 3 and 4). All the patients who received ADO Amplatzer devices (six patients with pmVSD and one muscular VSD) had no arrhythmia or conduction abnormality at either immediate or long-term follow up.

Interestingly, we noted resolution of ICRBBB in two of the four who had it at baseline EKG before closure and both had normal EKG at all follow-up visits. Of the other two patients of ICRBBB at baseline, one progressed to CRBBB and one maintained the same after device closure.

For all groups at long-term follow up, no mortality, stroke or neurologic deficit, device migration, wire fracture, thromboembolism, endocarditis, or hemolysis was seen.

\section{Discussion}

Nonsurgical closure of VSD has been an attractive option to avoid artificial circulation and sternotomy scars. The Amplatzer muscular occluder has been successfully used to close muscular VSDs $[6,7]$ and a specially designed Amplatzer ventricular septal occluder has been used in perimembranous defects $[8,10,14]$. The Amplatzer duct occluder has been used successfully for the closure of tunnel-type VSDs with aneurysmal tissue [11, 12]; recently, ADO - II has been tried with good success rates and minimal rhythm disturbances [13]. One of the major drawbacks for membranous VSD closure is the significant incidence of heart block and rhythm abnormality. In one study, the CAVB was reported as high as 5.8\% [17] with the need for pacemaker therapy. In other studies, the major adverse events have been reported as low as $0.6 \%$ in pmVSD patients under 3 years of age using symmetrical devices [15]. Late occurrence of CAVB also has been reported at 1 year follow up [20]. The junctional rhythm at early (within 48 hours) post-device pmVSD implantation indicates an inflammatory process around the atrioventricular node. Some studies showed occurrence of early post-implantation junctional rhythm up to $14 \%$ of their patients [15]. This can explain the observed benefit of steroid administration in some patients who developed CAVB early post-device implantation [15].

We showed a low incidence of CAVB in one (2.9\%) patient in the pmVSD group with a mean follow up of 62 months. This patient developed CAVB between 6 and 12 months post-implantation, remained asymptomatic, and was diagnosed by routine EKG. This warrants the necessity of long-term follow up of all 


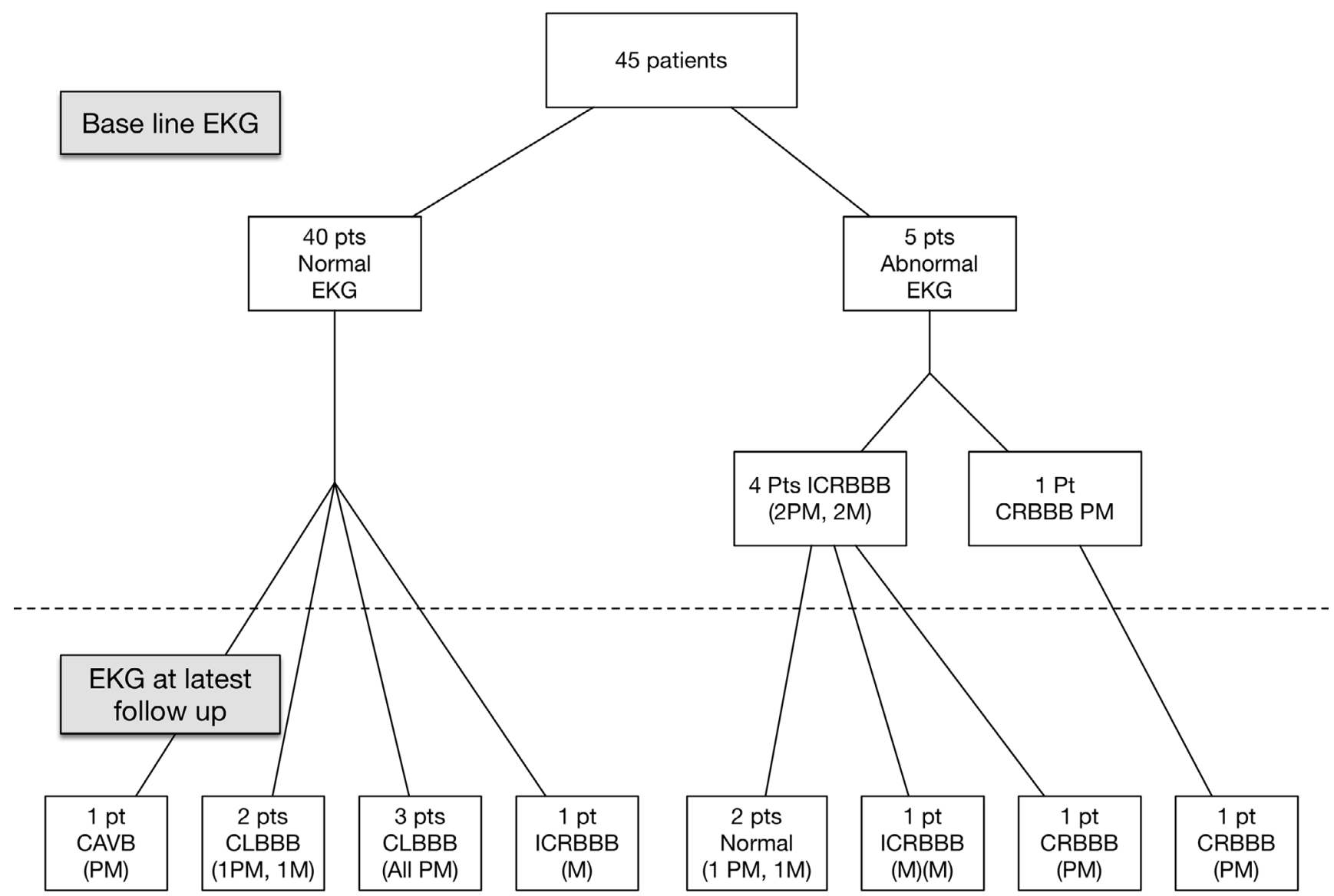

Figure 1. EKGs at baseline and at latest follow up. CAVB = complete atrioventricular block; CLBBB = complete left bundle brach block; $C$ RBBB = complete right bundle branch block; ICRBBB = incomplete right bundle branch block; PM = perimembranous VSD; $\mathrm{M}=$ membranous VSD.

patients with VSD device closure. CAVB has been reported in up to $5.8 \%$ with an asymmetric Amplatzer device [17] and as low as $0.1 \%$ with symmetrical occluders [15]. Acute (within 48 hours) and late (at 5 and 12 months post-procedure) CAVB in pmVSD was noted by Carminati et al. [18]. Independent risk factors for CAVB include younger age, low body weight, oversized device, type of device, repeated maneuvers, and position of defects [17-19]. Butera et al. [20] reported two cases of late-onset CAVB at 4 and 12 months after the procedure. Up to 30 days after Amplatzer VSD device closure, recovery of various forms of arrhythmias and heart block with corticosteroid therapy was observed [21, 22]. CAVB has been recovered in 70\% of the patients within 2 weeks post-procedure after being treated with steroids and isoprenaline [16].
We observed other"benign" conduction and rhythm disturbances in about $12 \%$ of the pmVSD group. Of those $12 \%$, there was only one patient who developed LBBB, which is less frequent than that reported in other studies. This LBBB didn't progress during 5 years of follow up. The pmVSD patients with aneurysmal tissue (six patients) that were closed by ductal occluders (ADO) did not show any rhythm disturbances. This may encourage investigators to utilize this approach whenever possible to avoid rhythm complications. The other interesting finding in our study was the resolution of IRBBB post-device implantation in two out of four patients who had it at baseline. This observation could be secondary to the decrease in right ventricular volume overload after stopping the left-to-right shunt. Our reported benign conduction 
disturbances in pmVSD are similar to another report of $12 \%$ CRBBB [10]. CLBBB has been reported at an incidence of 3.7\% [16]; however, the incidence of CLBBB was lower at $1.1 \%$ using the symmetrical VSD occluder [15].

Overall, our reported incidence of CAVB post-pmVSD device closure is similar to that reported for surgical closure. Certainly the occurrence of "benign" conduction disturbances with device closure is far fewer than that seen in surgical closures.

At 54.5 months mean echocardiographic follow up, complete VSD closure was observed in $91.2 \%$ of patients, whereas a small $(1-2 \mathrm{~mm}$ in size by transthoracic echo) residual shunt was found in $8.8 \%$ of patients. This is similar to other reports that noted a success rate of $92-97.6 \%[7,9,16]$.

\section{Conclusion}

Transcatheter closure of perimembranous and muscular VSDs has a high success rate with an adequate safety margin. Heart block following device closure is comparable to the surgical approach. Other rhythm disturbances in VSD device closure are far fewer than those of postsurgical closure. Rhythm disturbances at late follow up are uncommon but warrant close follow up.

\section{Acknowledgments}

We are very thankful to Dr. William Greer for his contributions on statistical analysis of the data in this paper. We also Thank Dr Reyaz A. Lone for his help in preparation of the manuscript.

\section{Conflict of Interest}

The authors have no conflict of interest relevant to this publication.

\section{Comment on this Article or Ask a Question}

\section{References}

1. Lewis DA, Loffredo CA, Corre-Villasenor A, Wilson PD, Martin GR. Descriptive epidemiology of membranous and muscular ventricular septal defects, the Baltimore-Washington infant study. Cardiol Young. 1996;6:281-290. DOI: 10.1017/ S1047951100003905

2. Kirklin JW, Barratt-Boyes BG, eds. Cardiac Surgery, 2nd ed. New York: Churchill Livingstone;1993.

3. Hardin JT, Muskett AD, Canter CE, Martin TC, Spray TL. Primary surgical closure of large ventricular septal defects in small infants. Ann Thorac Surg. 1992;53:397-401. DOI: 10.1016/0003-4975(92)90257-5

4. Nygren A, Sunnegardh J, Berggren $H$. Preoperative evaluation and surgery in isolated ventricular septal defects: A 21-year perspective. Heart. 2000;83: 198-204. DOI: 10.1136/heart.83.2.198

5. Andersen $\mathrm{H} \varnothing$, de Leval MR, Tsang TV, Elliott MJ, Anderson RH, Cook AC. Is complete heart block after surgical closure of ventricular septum defects still an issue? Ann Thorac Surg. 2006;82:948-956. DOI: 10.1016/j.athoracsur.2006.04.030

6. Arora R, Trehan V, Thakur AK, Mehta V, Sengupta PP, Nigam M. Transcatheter closure of congenital muscular ventricular septal defect. J Interv Cardiol. 2004;17:
109-115. DOI: $\quad 10.1111 / \mathrm{j} .1540-$ 8183.2004.09872.x

7. Holzer R, Balzer D, Cao QL, Lock K, Hijazi ZM. Device closure of muscular ventricular septal defects using the Amplatzer muscular ventricular septal defect occluder: immediate and mid-term results of a U.S. registry. J Am Coll Cardiol. 2004;43: 1257-1263. DOI: $\quad 10.1016 / \mathrm{j}$. jacc.2003.10.047

8. Pedra CA, Pedra SR, Esteves CA, Pontes SC $\mathrm{Jr}$, Braga SL, Arrieta SR, et al. Percutaneous closure of perimembranous ventricular septal defects with the Amplatzer device: technical and morphologic considerations. Catheter Cardiovasc Interv. 2004;61:403410. DOI: $10.1002 / c c d .10797$

9. Fu YC, Bass J, Amin Z, Radtke W, Cheatham $J P$, Hellenbrand WE, et al. Transcatheter closure of perimembranous ventricular septal defects using the new Amplatzer membranous VSD occluder. J Am Coll Cardiol. 2006;47:319-325. DOI: 10.1016/j. jacc.2005.09.028

10. Pinto RJ, Dalvi BV, Sharma S. Transcatheter closure of perimembranous ventricular septal defects using Amplatzer asymmetric ventricular septal defect occluder: Preliminary experience with 18-month follow up. Catheter Cardiovasc Interv. 2006;68:145-152. DOI: 10.1002/ccd.20813

11. Tan CA, Levi DS, Moore JW. Percutaneous Closure of Perimembranous Ventricular Septal Defect Associated With a Ventricular Septal Aneurysm Using the Amplatzer Ductal Occluder. Catheter Cardiovasc Interv. 2005;66:427-31. DOI: 10.1002/ ccd.20499

12. Muhammad D, Ahmad Z. Safety and efficacy of Amplatzer duct occluder for percutaneous closure of ventricular septal defects with tunnel shape aneurysm: Medium term follow up. World J Cardiovasc Dis. 2013;3:228-233. DOI: 10.4236/ wjcd.2013.32035

13. Koneti NR, Sreeram N, Penumatsa RR, Arramraj SK. Transcatheter retrograde closure of perimembranous ventricular septal defects in children with the Amplatzer duct occluder II device. J Am Coll Cardiol. 2012;60:2421-2422. DOI: 10.1016/j. jacc.2012.08.1004

14. Tzikas A, Aguirre D, Velasco-Sanchez D, Freixa $X$, Alburquenque $M$, Khairy $P$, et al. Transcatheter closure of perimembranous ventricular septal defect with the Amplatzer $^{\circledast}$ membranous VSD occluder 2: Initial world experience and one-year 
follow-up. Catheter Cardiovasc Interv. 2013. DOI: $10.1002 / c c d .25004$

15. Wang L, Cao S, Li J, Yang L, Liu Y. Transcatheter closure of congenital perimembranous ventricular septal defect in children using symmetric occluders: An 8-year multi institutional experience. Ann Thorac Surg. 2012;94;592-598. DOI: 10.1016/j. athoracsur.2012.03.067

16. Zuo J, Xie J, Yi W, Yang J, Zha J. Results of transcatheter closure of perimembranous ventricular septal defect. Am J Cardiol. 2010;106:1034-1037. DOI: 10.1016/j.amjcard.2010.05.040

17. Butera G, Carminati M, Chessa M, Piazza L, Micheletti A, Negura DG, et al. Transcatheter closure of perimembranous ventricular septal defects: early and Long-term results. J Am Coll Cardiol. 2007;50:1189-1195. DOI: 10.1016/j.jacc.2007.03.068

18. Carminati M, Butera G, Chessa M, Drago M, Negura D, Piazza L. Transcatheter closure of congenital ventricular septal defect with Amplatzer septal occluders. Am J Cardiol. 2005;961:52L-58L. DOI: 10.1016/j.amjcard.2005.09.068

19. Qin Y, Chen J, Zhao X, Liao D, Mu R, Wang $S$, et al. Transcatheter closure of perimembranous ventricular septal defect using a modified double-disk occluder. Am J Cardiol. 2008;101:1781-1786. DOI: 10.1016/j. amjcard.2008.02.069

20. Butera G, Massimo C, Mario C. Late complete atriovenous block after percutaneous closure of a perimembranous ventricular septal defect, Catheter Cardiovasc Interv. 2006;67:938-941. DOI: 10.1002/ ccd.20696

21. Sun XJ, Gao W, Zhou AQ, Yu ZQ, Li F, Huang $M R$, et al. Risk factors for arrhythmia early after transcatheter closure of peri-membranous ventricular septal defects. Zhonghua Er Ke Za Zhi. 2005;43:767-771. PMID: 16255857
22. Zhang YS, Li H, Liu JP, Dai ZX, Wang L, Zhang J, et al. Complications of transcatheter interventional occlusion of ventricular septal defects. Zhonghua Er Ke Za Zhi. 2005;43:35-38. PMID: 15796806

Cite this article as: Dilawar $M$, Rahmath MRK, Al-Hroob A, El-Said HG, Sisi AE, Morcos S, Numan M. Low Incidence of Rhythm Disturbance following Percutaneous Closure of Ventricular Septal Defects using the Amplatzer Device at Immediate-to-Long-Term Follow Up. Structural Heart Disease 2016; 2(1):35-41. DOI: http://dx.doi. org/10.12945/j.jshd.2015.005.14 